\title{
Competências da enfermeira para a triagem clínica de doadores de sangue
}

\author{
Nurse's competencies for clinic screening of blood donors \\ Competencias de la enfermera para la tamizage clínica de donadores de sangre
}

\section{Débora Zmuda Padilha', Regina Rigatto Witt'}

'Universidade Federal do Rio Grande do Sul. Escola de Enfermagem. Porto Alegre, RS

Submissão: 23/1 1/2009

Aprovação: 20/11/2010

\section{RESUMO}

O objetivo desta peseuisa foi identificar competências da enfermeira para a triagem de doadores de sangue, dentre as preconizadas pelo Conselho Internacional de Enfermagem. Tratpu-se-se de um estudo Qualitativo do tipo estudo de caso. Foi realizado no Serviço de Hemoterapia - Unidade Banco de Sangue de um hospital universitário da cidade de Porto Alegre, RS, Brasil. Foram observadas 25 entrevistas de cinco enfermeiras que trabalhavam no setor. Para a análise das observações foi utilizada a adeQuação ao padrão. Foram identificadas seis competências da área prática profissional, ética e legal e onze da área provisão e gerenciamento do cuidado. As competências identificadas neste estudo contribuem para o preparo e prática das enfermeiras generalistas na a realização da triagem clínica de doadores de sangue.

Descritores: Competência profissional; Conselho Internacional de Enfermagem; Doadores de sangue.

\section{ABSTRACT}

This investigation aimed at identifying nurse's competencies necessary to screen blood donors, from those recommended by the International Council of Nurses. A Qualitative, descriptive case study was developed at the Hemotherapy Service - blood bank of a teaching hospital in Porto Alegre, RS, Brazil. Twenty Five interviews performed by five nurses hired by the service were observed. For observations analysis standard adequacy was used. Six competencies of the professional, ethics and legal area and eleven from care provision and management were identified. Competencies identified in this study will serve as a basis for practice and to prepare generalist nurses to perform clinic screening of blood donors.

Key-words: Professional competence; International Council of Nurses; Blood donors.

\section{RESUMEN}

El objetivo de esta investigación fue identificar competencias de la enfermera necesarias para la tamizage de donadores de sangre, dentre las preconizadas por el Consejo Internacional de Enfermería. Es un estudio cualitativo, descriptivo del tipo estudio de caso. Fue desarrollado en el Servicio de Hemoterapia - Unidad Banco de Sangre de un Hospital Universitario de Porto Alegre, RS, Brasil. Fueran observadas 25 entrevistas de cinco enfermeras Que trabajan en el sector. Para el análisis de las observaciones fue utilizada la adeQuación al padrón. Fueran identificadas seis competencias del área práctica professional, ética y legal y onze del área provisión y gerenciamiento del cuidado. Las competências identificadas en este estudio servirán para el preparo y práctica de las enfermeras generalistas en la realización de la tamizage clínica de donadores de sangre.

Descriptores: Competencia profesional; Consejo Internacional de Enfermería; Donadores de sangre. 


\section{INTRODUÇÃO}

A triagem clínica de doadores de sangue tem o objetivo de proteger tanto os doadores de sangue, Quanto os pacientes Que vão receber a transfusão. Este procedimento consiste na avaliação da história clínica e epidemiológica do doador, do estado atual de saúde, dos hábitos e comportamentos do candidato à doação para determinar se ele está em condições de doar o sangue ${ }^{(1)}$. A realização da triagem clínica deve ser feita por um profissional de saúde capacitado, de nível superior, Qualificado e conhecedor das normas Que avaliará os antecedentes e o estado atual do candidato ${ }^{(2)}$.

O triador precisa ter uma habilidade e sensibilidade para analisar as informações e as expressões do candidato à doação, também precisa manter uma postura ética, sigilo de todas as informações, comunicação adeQuada e passar segurança para o doador $^{(1-3)}$. É na entrevista da triagem clínica Que se pode identificar as situações de risco para a janela imunológica, uma vez Que a transmissão de doenças pelo sangue não pode ser totalmente evitada com a realização dos testes sorológicos.

Os profissionais de saúde durante a triagem precisam demonstrar familiaridade com as perguntas do Questionário, lidar com Questões Que se referem à intimidade do doador e ter grande preparo técnico e emocional, pois cada doador tem uma história diferente $^{(3)}$.

Além da grande demanda, do trabalho exaustivo, a omissão dos doadores durante a entrevista em relação a determinadas perguntas também pode acontecer ${ }^{(3-4)}$.

Com isso é de extrema importância Que a triagem clínica seja feita de forma rigorosa, chamando a atenção para todas as informações Que os doadores passarão durante a entrevista, evitando posteriormente uma possível infecção, sendo necessárias para a enfermeira competências específicas para a realização desta atividade. A Resolução COFEN 306 de 2006 fixa as competências e atribuições do Enfermeiro na área de Hemoterapia ${ }^{(5)}$.

A triagem clínica por se tratar de um processo investigativo, visa à segurança do processo de doação, ao mesmo tempo é considerado um momento de educação e cuidado dos doadores. As enfermeiras Que realizam esta atividade integram a educação, o conhecimento, a consultoria, a perícia e a peculiaridade para realizar a triagem. A importância das competências educacionais da enfermeira tem sido descrita na literatura ${ }^{(6)}$.

Este estudo visa identificar as competências de enfermeira generalista necessárias para a triagem clínica de doadores de sangue, já Que para atuar nos Bancos de Sangue atualmente não é exigida uma especialização em hemoterapia e as enfermeiras Que compõem este serviço são de maioria generalista, adeuirindo a experiência no trabalho.

Para isto, foi utilizada uma estrutura de competências desenvolvida pelo Conselho Internacional de Enfermeiras (CIE) para a enfermeira generalista ${ }^{(7)}$.

Sendo assim, o objetivo desse estudo foi identificar Quais as competências da enfermeira são necessárias para a triagem de doadores de sangue, dentre as preconizadas pelo CIE.

\section{MÉTODO}

Tratou-se de um estudo Qualitativo do tipo estudo de caso $^{(8-9)}$.
O estudo foi realizado no Serviço de Hemoterapia - Unidade Banco de Sangue do Hospital de Clínicas de Porto Alegre (HCPA), hospital universitário da Universidade Federal do Rio Grande do Sul (UFRGS).

No Banco de Sangue atuam cinco enfermeiras fixas, contratadas para atuar no Serviço de Hemoterapia, distribuídas nos turnos manhã, tarde e final de semana e enfermeiras de outros setores do hospital, Que tem uma atuação sob forma de ação diferenciada (AD) pela manhã ou pela tarde uma vez na semana no serviço.

Para a seleção dos sujeitos foi considerado o respeito e a valorização da experiência e do conhecimento de cada um dos participantes $^{(10)}$. Considerando estes critérios, foram selecionadas todas as enfermeiras contratadas (5) pelo HCPA Que trabalham no Serviço de Hemoterapia, por estarem realizando esta atividade diariamente e por terem mais experiência devido à carga horária e ao tempo de atuação neste serviço.

Assim, o critério de inclusão para o estudo foi ser enfermeira fixa da Unidade de Banco de Sangue do HCPA que realize entrevista clínica de doadores e o critério de exclusão foi ser enfermeira de hora extra ou AD de outros serviços do HCPA.

A coleta de dados foi realizada por meio de observação estruturada e gravação da atividade triagem de doadores de sangue. Foram observadas 25 entrevistas, cinco de cada enfermeira.

A pesquisadora usou como guia para observação a ficha de triagem disponibilizada pelo HCPA. Esta ficha teve a finalidade de avaliar se as perguntas foram realizadas em sua totalidade pela enfermeira. O instrumento é composto por 26 perguntas Que avalia o estado de saúde dos doadores de sangue, investigando a história prévia de doenças, vacinas, cirurgias, tatuagens, vida sexual e viagens.

A análise dos dados foi baseada na adequação ao padrão, Que compara um padrão fundamentalmente empírico com outro de base prognóstica $^{(11)}$. Foi utilizado como padrão o referencial de competências para enfermeiras generalistas do CIE. A estrutura do CIE apresenta as competências da enfermeira generalista em três categorias: Prática Profissional, Ética e Legal, Provisão e Gerenciamento do Cuidado e Desenvolvimento Profissional ${ }^{(7)}$.

As gravações foram transcritas, assinalando-se as perguntas Que compõem o roteiro da triagem das outras falas como indagações ou orientações Que as enfermeiras realizaram no decorrer da triagem clínica.

Os princípios éticos foram respeitados, de acordo com a Resolução 196/96 do Conselho Nacional de Saúde ${ }^{(12)}$. A devolução do Termo de Consentimento Livre e Esclarecido (TCLE) da enfermeira preenchido formalizou o consentimento do informante em participar do estudo. A devolução do TCLE do doador preenchido autorizou a realização da observação e gravação de sua triagem. A fim de preservar a identidade das enfermeiras observadas, foram utilizados os grupos sangüíneos $(\mathrm{A}+, \mathrm{B}+, \mathrm{AB}+, \mathrm{O}+\mathrm{e} \mathrm{Rh})$ na apresentação dos resultados. $\mathrm{O}$ projeto foi aprovado pelo Comitê de Ética e Pesquisa do Hospital de Clínicas de Porto Alegre (GPPG/ HCPA), protocolo número 08-347.

\section{RESULTADOS E DISCUSSÃO}

A análise das entrevistas evidenciou competências da enfermeira para a triagem de doadores de sangue relacionadas às catego- 
rias prática profissional, ética e legal (6) e à provisão e gerenciamento do cuidado (l l l). Estas competências estão apresentadas no Quadro a seguir.

\section{Pratica Profissional, Ética e Legal}

Na sub-categoria prestação de contas, foi identificada a competência "consulta com outros profissionais de saúde e organizações/instituições Quando as necessidades individuais ou de grupo estão além do alcance da sua prática de enfermagem". Esta competência foi identificada nas situações a seguir.

O doador referiu um tratamento para infecção urinária e inflamação no útero. A enfermeira Questionou:

Quando isso? Faz seis meses? Deixa eu perguntar para a douto$\mathrm{ra!}(\mathrm{AB}+)$

A Resolução da Diretoria Colegiada - RDC n 153 de 14 de julho de 2004 é a lei Que rege atualmente sobre os Serviços de Hemoterapia no Brasil. Conforme a RDC, o doador não deve apresentar nenhuma enfermidade infecciosa aguda, sendo excluído temporariamente até a cura definitiva ${ }^{(2)}$.

Outra consulta realizada com outros profissionais de saúde acontece na entrevista a seguir, na Qual o doador de aférese comeu batatas fritas.
Hoje tu não comeu nada com gorduras? Nada frito assim? Vou perguntar para a doutora se pode um pouquinho de batata frita. $(\mathrm{AB}+)$

Esta competência também foi identificada na entrevista clínica a seguir com a dúvida da enfermeira Quanto às respostas confusas e de risco sexual que o doador referiu.

Eu vou falar com a médica, vou explicar teu caso para ela, porque tem muitas coisas que tu não pode doar. Eu vou explicar para ela teu caso para ver se ela libera tua doação ou não. $(\mathrm{B}+)$

Na RDC consta como inaptidão à doação de sangue durante 12 meses, todas as pessoas Que tenham feito sexo com um ou mais parceiros ocasionais ou desconhecidos, sem o uso de preservativo pelo risco da janela imunológica ${ }^{(2)}$.

Na sub-categoria prática ética, foram identificadas as competências "assegura sigilo e segurança da informação escrita e verbal adeuirida em uma situação profissional" e "respeita o direito do paciente/cliente à privacidade".

Estas competências foram identificadas em todas as entrevistas de doadores de sangue, pois a triagem clínica, conforme a RDC deve ser realizada em salas reservadas e sem interrupções, sendo

\begin{tabular}{|c|c|c|}
\hline \multicolumn{3}{|c|}{ PRÁTICA PROFISSIONAL, ÉTICA E LEGAL } \\
\hline Prestação de Contas & \multicolumn{2}{|c|}{$\begin{array}{l}\text { 1. Consulta com outros profissionais de saúde e organizações/instituições quando as necessidades } \\
\text { individuais ou do grupo estão além do alcance da sua pratica de enfermagem. }\end{array}$} \\
\hline Prática Ética & \multicolumn{2}{|c|}{$\begin{array}{l}\text { 2. Assegura sigilo e segurança da informação escrita e verbal adQuirida em uma situação profissional; } \\
\text { 3. Respeita o direito do paciente/cliente à privacidade; } \\
\text { 4. Identifica prática insegura e toma as providências apropriadas. }\end{array}$} \\
\hline Prática Legal & \multicolumn{2}{|c|}{$\begin{array}{l}\text { 5. Pratica de acordo com a legislação vigente; } \\
\text { 6. Pratica de acordo com as políticas nacional e local e com as diretrizes normativas. }\end{array}$} \\
\hline \multicolumn{3}{|c|}{ PROVISÃO E GERENCIAMENTO DO CUIDADO } \\
\hline $\begin{array}{l}\text { Princípios gerais da } \\
\text { provisão do cuidado e } \\
\text { gerenciamento }\end{array}$ & \multicolumn{2}{|c|}{$\begin{array}{l}\text { 1. Aplica conhecimento e habilidades relevantes à prática de enfermagem; } \\
\text { 2. Aplica o pensamento crítico, e habilidades de resolução de problemas; } \\
\text { 3. Aplica julgamento clínico e tomada de decisão em uma variedade de contextos profissionais e de } \\
\text { prestação de cuidados; } \\
\text { 4. Justifica o cuidado de enfermagem; } \\
\text { 5. Apresenta informação clara e sucintamente; } \\
\text { 6. Interpreta apuradamente dados objetivos e subjetivos e seu significado para a prestação de cuidado } \\
\text { seguro. }\end{array}$} \\
\hline \multirow{3}{*}{ Provisão do cuidado } & A promoção da saúde & $\begin{array}{l}\text { 7. Reconhece o potencial para o ensino da saúde nas intervenções } \\
\text { de enfermagem }\end{array}$ \\
\hline & Planejamento & $\begin{array}{l}\text { 8. Assegura Que pacientes/clientes e/ou cuidadores recebam e } \\
\text { compreendam informação para basear o consentimento para o } \\
\text { cuidado }\end{array}$ \\
\hline & $\begin{array}{l}\text { Comunicação terapêutica e } \\
\text { relacionamento interpessoal }\end{array}$ & $\begin{array}{l}\text { 9. Assegura Que a informação dada ao paciente ao paciente/cliente } \\
\text { e/ou cuidadores é apresentada de maneira apropriada e clara; } \\
\text { 10. Responde apropriadamente às perguntas, solicitações e } \\
\text { problemas do paciente/cliente e/ou cuidador. }\end{array}$ \\
\hline $\begin{array}{l}\text { Gerenciamento } \\
\text { do cuidado }\end{array}$ & Ambiente seguro & 1 1. Implementa procedimento de controle de infecção. \\
\hline
\end{tabular}

Quadro I. Competências da Estrutura do Conselho Internacional de Enfermeiras para a Enfermeira Generalista identificadas na entrevista de triagem de doadores de sangue por categorias e sub-categorias. Porto Alegre, 2008. 
Que todas as informações prestadas pelo doador deverão ser sigilosas, antes, durante e depois do processo de doação ${ }^{(2)}$. Além disso, é fundamental Que a entrevista seja realizada em um espaço de privacidade para Que o candidato se sinta a vontade para expor aspectos de sua vida, apresentando confiança no profissional Que está the Questionando.

Outra competência da categoria prática ética é "identifica prática insegura e toma as providências apropriadas" Que apareceu nas triagens abaixo.

Deixa eu ver, estou notando Que tu estás com uma bolinha ali no olho [...] inter-sol tu não teve? $(\mathrm{A}+)$

Uhm... esse braço tem uma descamação oh! Vai ter Que dar esse braço aqui para puncionar, porque o outro elas não vão puncionar por causa dessa descamação. [...] Daí tu diz para ela puncionar o braço direito. $(\mathrm{O}+)$

Neste caso, a enfermeira avaliou e considerou o doador assintomático no momento da doação. No caso dos sintomáticos, são inaptos definitivos aqueles Que padecem de enfermidades atípicas graves, como por exemplo, asma brôneuica grave ${ }^{(2)}$ e durante a crise alérgica o doador fica impedido de doar, pois tem substâncias (imunoglobulinas) circulando no seu sangue Que podem passar para o paciente e causar reações ${ }^{(1)}$.

Nesta entrevista a enfermeira identifica o emagrecimento do doador e o Questiona sobre o seu peso, tomando as providências necessárias.

[...] teu peso chega a $50 \mathrm{~kg}$ ? A última vez Que tu se pesou foi Quando? Vamos lá se pesar para confirmar! (A+)

O peso mínimo para um candidato ser aceito é de $50 \mathrm{~kg}^{(2)}$. Este peso possibilita que a cota do volume de sangue possa ser retirado sem danos para sua saúde ${ }^{(1)}$.

$\mathrm{Na}$ entrevista a seguir a enfermeira Questiona o doador a respeito da sua pressão, pois ele confirma Que tem o diagnóstico de hipertensão, mas não usa medicação diária. Doadores com a pressão arterial alterada são inaptos para a doação de sangue pelas reações Que podem acontecer no decorrer da doação.

Toma medicação? O Que tu toma? Mas não toma todo dia?... Então como sabe Que tem pressão alta? $O$ médico não pediu para tomar medicação todo dia? $(\mathrm{O}+)$

$\mathrm{Na}$ entrevista a seguir é identificada a prática insegura do doador.

Então assim, tu não vai poder doar, porQue tu já tiveste mais de uma parceira sexual no ano sem o uso de preservativo. $(\mathrm{B}+)$

A triagem clínica é muito importante, uma vez que a transmissão de doenças pelo sangue pode não ser totalmente evitada com a realização dos testes sorológicos ${ }^{(2)}$.

Na sub-categoria prática legal, foram identificadas duas competências da enfermeira durante a triagem clínica de doadores de sangue sendo estas, "pratica de acordo com a legislação vigente" e "pratica de acordo com as políticas nacional e local e com as diretrizes normativas".

Os bancos de sangue seguem a legislação vigente RDC 153 de 14 de junho de 2004. Portanto a competência pratica de acordo com a legislação vigente aparece em todas as situações na triagem, pois tudo Que as enfermeiras Questionam é referente à lei.

Em uma das entrevistas aparece um caso de hipotensão. A enfermeira reconhece a situação vivenciada e informa sua decisão.

Está bem baixa tua pressão, $80 / 55 \mathrm{mmHg}$, o problema é Que com ela assim tu não vai poder doar. $(\mathrm{A}+)$

Conforme a Lei RDC 153, para doação de sangue, a pressão sistólica não deve ser maior Que $180 \mathrm{mmHg}$ e nem inferior a 90 $\mathrm{mmHg}$, e a pressão diastólica não deve ser menor Que $60 \mathrm{mmHg}$ nem maior Que $100 \mathrm{mmHg}^{(2)}$.

Ainda na situação do doador Que teve infecção urinária e inflamação vaginal há mais ou menos 6 meses, evidenciou-se em outra fala esta competência no momento em Que a enfermeira explica para o doador o porøuê da inaptidão, conforme a legislação(l)

O Que a legislação diz! Não sei o Que tu teve, tu também não sabe me explicar, disse que teve um corrimento mas não me deu o nome. A legislação diz que Quem teve alguma coisa nos genitais assim, tem Que esperar I ano para poder doar novamente. $(\mathrm{AB}+)$

A competência "pratica de acordo com as políticas nacional e local e com as diretrizes normativas" aparece na entrevista a seguir:

Quando o doador é frequente, ele pode entrar para o clube de doadores aqui do hospital e assim, a vantagem que tu tem é Que não precisa esperar. Quando tu chega, passa na frente dos outros doadores, que é uma coisa que motiva o doador, pois muitos não vem por falta de tempo. ( $\mathrm{A}+)$

O Banco de Sangue do HCPA tem em sua política local o Clube de Doadores onde os doadores espontâneos com mais de três doações podem se cadastrar e participar. O enfermeiro deve ser capaz de através da relação, da comunicação e da interação com o doador, envolvê-lo no contexto da dádiva de sangue, fornecendolhe o ensino dos cuidados e promover a sua fidelização à doação de sangue ${ }^{(13)}$.

\section{Provisão e Gerenciamento do Cuidado}

\section{Princípios centrais da provisão e gerenciamento do cuidado}

A competência "aplica conhecimento e habilidades relevantes à prática de enfermagem" foi identificada em uma entrevista em Que o cliente pergunta o que muda Quando a pessoa doa sangue e ela responde:

...o Que muda é que nos próximos 3 dias tu vai estar com menos líquido no teu organismo, tem que tomar um pouco mais de líquido do que costuma [...] é bom fazer duas refeições de sal durante o dia, porQue a tua pressão pode baixar um pouQuinho. $(\mathrm{A}+)$ 
Nesta entrevista a enfermeira aplica seus conhecimentos Quanto à atividade física realizada.

[...] é bom que não faça força com o braço que for doar, porque Quando acontece é um hematoma doloroso, o braço fica inchado e ai custa um tempo até absorver, ta? Se acontecer aplicar gelo. $(\mathrm{A}+)$

O gelo promove a vasoconstrição local e evitará a formação de grandes hematomas. Deve ser prolongado por 24 horas, deixando sempre períodos de repouso, sendo recomendada a aplicação de gelo por cada 15 minutos por dez minutos de descanso, para evitar a lesão de estruturas nervosas na região atingida ${ }^{(14)}$.

Em algumas situações, apareceram mais de uma competência da enfermeira, como é o caso da entrevista a seguir:

Não assim, Quem comeu arroz, feijão carne, o mínino pra digestão da carne é 8 horas né? A legislação dá 4 horas e no banco de sangue a combinação é assim, depois Que almoça tem Que esperar 2 horas para poder doar o sangue. $(\mathrm{AB}+)$

Ao mesmo tempo em Que a enfermeira aplica seus conhecimentos para explicar e justificar o porquê deste impedimento, ela baseia-se nas leis nacional e local, para explicar sua decisão(I).

A competência "aplica pensamento crítico e habilidades de resolução de problemas" aparece na situação em Que a enfermeira se depara com um motorista de caminhão na triagem clínica de doadores de sangue. A partir deste momento ela começa a Questionálo:

O senhor é motorista de caminhão? Para que cidades o senhor viaja? Região nordeste, norte o senhor nunca vai? Tem viajem marcada? O senhor não usa aquelas medicações para ficar acordado? $(\mathrm{A}+)$

O interessante nessa entrevista é observar o pensamento critico e rápido Que a enfermeira fez com apenas uma informação do doador. Aproveitou e o Questionou sobre as viagens para se certificar Que ele não viaja para as áreas de malária e também se não usa medicações já Que algumas são impeditivas. Também solicita informação sobre viagens programadas, pois a legislação prevê Que operadores de máeuina, condutores de veículos coletivos devem interromper suas atividades por $12 \mathrm{~h}$ depois da coleta ${ }^{(2)}$.

A competência "aplica julgamento clínico e tomada de decisão em uma variedade de contextos profissionais e de prestação de cuidados" foi encontrada nas entrevistas a seguir.

A enfermeira pergunta se o cliente tem algum problema de saúde, aproveitando sua resposta, ela faz o julgamento clínico fazendo mais perguntas, para realmente certificar-se Que o cliente é saudável.

Chegaste a fazer alguma endoscopia para ver essa gastrite? Esse omeprazol é indicação médica? Quanto tempo faz Que tomou? (Rh)

Os doadores Que foram submetidos a exames de endoscopia ou broncoscopia devem esperar um período de um ano para poder doar sangue, pois por mais seguros Que sejam estes exames, existem evidências de contaminação nos exames de endoscopia por pseudômonas aeruginosa ${ }^{(15)}$.

Outra competência encontrada foi "justifica o cuidado de enfermagem prestado" em duas entrevistas nas Quais as enfermeiras explicam e justificam a importância da ingesta hídrica e alimentar após a doação.

Procura tomar bastante líquido hoje tá? Para repor essa Quantidade de $500 \mathrm{ml}$ de sangue Que tu vai doar hoje. Não faz atividade física, não carregar peso para não criar hematoma. $(\mathrm{B}+)$

Vai ter Que fazer um lanche antes. [...] Não o negócio é antes, tu tens Que tomar liquido porQue tu vai poder ter tontura em função de estar com pouco volume de liquido no organismo. (Rh)

Em relação à competência "apresenta informação clara e sucintamente", na entrevista abaixo o doador apresentou várias informações consideradas de risco para a doação de sangue e a enfermeira informa os motivos pelos Quais ele não poderá doar.

Eu demorei e perguntei tudo isso, porQue tem o tempo da janela imunológica Que a gente chama, Quando as pessoas transam sem preservativos, tem um tempo para as doenças aparecerem, não Quer dizer Que vai aparecer, mas poderá. Ai é risco, daí a gente não libera aqui [...] (B+)

A janela imunológica corresponde ao período, a partir do contato com o agente infeccioso, em Que o organismo ainda não produz anticorpos em Quantidade suficiente para serem detectados nos testes de sorologia ${ }^{(4,16)}$.

A competência "interpreta apuradamente dados objetivos e subjetivos e seu significado para a prestação de cuidado seguro", foi identificada em um maior número de situações.

[...] o que deu na biópsia? Não precisou usar nenhuma medicação para a tireóide? [...] é medicação natural, fitoterápico? $(\mathrm{A}+)$

Na triagem acima, o doador refere Que o único problema de saúde Que tinha era três nódulos na tireóide. A enfermeira interpreta a resposta e pergunta sobre a biópsia e medicamentos, garantindo Que o sangue doado será seguro.

Em outra situação o doador refere ter utilizado antibiótico para tratar uma ferida no útero. A partir desta informação a enfermeira Questiona o doador para se certificar Que não há algo mais grave.

Para Que tomou a medicação? Ferida ainda tem? Chegou a fazer biópsia? Algum sangramento Que tenha? $(\mathrm{O}+)$

Algumas doenças são causas de inaptidão definitiva para a doação de sangue, dentre elas broneuite, asma, câncer, cardiopatias graves, diabetes, doenças de chagas, malária entre outras ${ }^{(2)}$.

Esta competência também foi bastante evidenciada nos Questionamentos sobre as práticas sexuais inseguras Que os doadores referem durante a triagem clínica. 
No último ano teve relações com prostitutas? Quanto tempo faz? E esse tempo faz mais ou menos Quanto? Foi com o uso de preservativos? $(\mathrm{B}+)$

Tem parceira fixa? Nesse último ano relações somente com sua parceira? As duas tu não utiliza preservativos? Esta com as duas juntas? $(\mathrm{B}+)$

Lidar com Questões sobre a intimidade de uma pessoa exige grande preparo tendo em vista Que a entrevista precisa de fatos verdadeiros ${ }^{(3)}$. No momento em Que as enfermeiras demonstram conhecimento sobre o Questionário da triagem clínica, acabam adQuirindo uma postura de total atenção no momento da entrevista, possibilitando uma melhor investigação Quando algo inseguro for observado.

\section{Provisão do cuidado}

Na sub-categoria da promoção da saúde foi identificada a competência "reconhece o potencial para o ensino da saúde nas intervenções de enfermagem."

Nas situações a seguir, as enfermeiras explicam o cuidado e as providências Que devem tomadas com a pressão arterial.

As pessoas com a pressão baixa, devem tomar bastante líquido, tá? Te alimenta bem nos próximas dias [...] (A+)

[...] te cuida guri, tem que controlar a pressão porQue a pressão alta é silenciosa né? Tu pode não ter sintoma nenhum, tem Que cuidar. $(\mathrm{O}+)$

Pois é, mas não dá para doar com essa pressão, ta muito alta. Tu é bem jovem, 24 anos para ter essa pressão. Tem que procurar o médico. Vai ter que tomar um remedinho, regular a alimentação. $(\mathrm{O}+)$

É importante enfocar o papel educativo da enfermeira na triagem clínica de doador de sangue, tendo em vista Que ela deverá esclarecer possíveis dúvidas, orientar os doadores sobre seu estado, assim como explicar os motivos porque não poderão realizar a doação(3).

Na sub-categoria planejamento, a competência evidenciada foi "assegura Que pacientes/clientes e/ou cuidadores recebam e compreendam informação para basear o consentimento para o cuidado".

A enfermeira assegura na triagem abaixo Que o doador compreendeu as informações do voto de auto-exclusão. O voto de auto-exclusão é um mecanismo Que tem por finalidade dar mais uma oportunidade a todos os doadores de forma sigilosa se seu sangue é adequado ou não para ser utilizado em transfusões ${ }^{(1)}$.

O senhor não consegue enxergar aQui? Então a pergunta é a seguinte. Considero meu sangue seguro para ser usado em outra pessoa? $(\mathrm{O}+)$

Na sub-categoria comunicação terapêutica e relacionamento interpessoal, a competência "assegura Que a informação dada ao paciente/cliente e/ou cuidadores é apresentada de maneira clara e apropriadamente" foi identificada nas falas abaixo:

Tem tendência a hemorragia? Quando te corta custa a parar de sangrar, fica hematoma? (Rh).

Nesta entrevista a enfermeira assegura Que a informação da pergunta obrigatória da legislação "tem tendência a sangramento?" seja apresentada ao doador de forma clara e apropriada, Quando ela explica o significado de hemorragia.

A competência "responde apropriadamente às perguntas, solicitações e problemas do paciente/cliente e/ou cuidador" foi identificada nas situações a seguir.

Nesta triagem, o doador pergunta se o sangue não é analisado depois da doação:

O sangue é analisado, mas Quando chega aqui uma situação de risco a gente não passa, por isso Que tem a triagem, QualQuer dúvida Que a gente tenha Que esteja fora das normas a gente pergunta para médica se ela libera para doação. $(\mathrm{B}+)$

\section{Gerenciamento do cuidado}

Na sub-categoria ambiente seguro foi evidenciada a competência "Implementa procedimentos de controle de infecção" durante as triagens. Em todas as situações Que esta competência apareceu se relacionava ao mesmo procedimento, à lavagem dos decúbitos dos braços antes de realizar a doação:

Depois ali na doação, Quando pedirem para lavar o braço, o senhor lava bastante no meio do braço, onde vai ser coletado. Que é porta de entrada para alguma bactéria na hora da punção. $(\mathrm{A}+)$

A lavagem dos braços é rotina do banco de sangue, recomendada para eliminar a flora bacteriana da pele do candidato antes de realizar o procedimento da punção.

\section{CONSIDERAÇÕES FINAIS}

Os resultados desta pesquisa fortalecem a importância da triagem clínica, como cuidado de enfermagem para o doador, no momento em Que realiza promoção à saúde, além de assegurar ao receptor a Qualidade do sangue a ser transfundido.

A enfermeira precisa compreender a individualidade de cada doador e, a partir disso, tomar as atitudes apropriadas. Para ser uma enfermeira triagista, não basta ter apenas o conhecimento da lei vigente, mas também precisa estar preparada para atender todas as situações Que vão surgir, tendo a habilidade para agir adeQuadamente a partir da individualidade de cada doador.

Em algumas entrevistas apareceram situações emocionais referente à vida do doador de sangue. Não conseguimos identificar nenhuma competência na estrutura do CIE para enfermeira generalista para o atendimento destas situações, porém é necessário Que se investiguem Quais seriam estas competências, pois a enfermeira precisa ter grande preparo emocional, tendo em vista Que muitas vezes os doadores vão doar em situações de grande tristeza, sempre Querendo ajudar a pessoa a Quem está se candidatando a doar. 
As competências identificadas neste estudo contribuem para a definição de elementos essenciais da profissão e a exploração da disposição e habilidades que os profissionais de saúde devem possuir para responder melhor às necessidades do público, constituindose como componentes críticos requeridos para o atendimento da função essencial de saúde pública de vigilância, prevenção e controle de enfermidades transmissíveis e não transmissíveis ${ }^{(17)}$.

Além disso, poderão servir de subsídio para a prática e para o preparo das enfermeiras generalistas para a realização da triagem clínica de doadores de sangue, assim como para a realização de futuras investigações com o intuito de identificar outras competências necessárias para a realização desta atividade.

\section{REFERÊNCIAS}

1. Ministério da Saúde (BR). Coordenação nacional de Doenças Sexualmente Transmissíveis e Aids. Triagem clínica de doadores de sangue. Brasília: Ministério da Saúde; 2001.

2. Ministério da Saúde (BR). Resolução da Diretoria Colegiada RDC $n^{\circ} 153$, de 14 de junho de 2004. Diário Oficial da União 2004; 24 jun.

3. Valadares GV, Viana LO. O trabalho da enfermeira na triagem clínica em hemoterapia: por uma especialização. Esc Anna Nery Rev Enferm 2003; 7(3):334-4I.

4. Carrazzone CFV, Brito AM, Gomes YM. Importância da avaliação sorológica pré-transfusional em receptores de sangue. Rev Bras Hematol Hemoter 2004; 26(2): 93-8.

5. Conselho Federal de Enfermagem (BR). Resolução n. 306 de 2006. Fixa as competências e atribuições do enfermeiro na área de hemoterapia. Brasília: COFEn; 2006. [citado em: 2009 nov 23]. Disponível: http://www.portalcofen.gov.br .

6. Backes VMS, Lino MM, Prado ML, Reibnitz KS, Canaver BP. Competência dos enfermeiros na atuação como educador em saúde. Rev Bras Enferm 2008; 61 (6): 858-65.

7. International Council of Nurses. ICN framework of competencies for the generalist nurses. Geneva: ICN; 2003.

8. Gil AC. Como elaborar projetos de pesQuisa. $4^{\mathrm{a}}$ ed. São Paulo: Atlas, 2002.

9. Polit DF, Hungler BP. Fundamentos de pesquisa em enferma- gem. $3^{\text {a }}$ ed. Porto Alegre: Artes Médicas; 1995.

10. Duffield C. The Delphi Technique: a comparison of results obtained using two expert panels. Int I Nurs Stud 1993; 30 (3): 227-37.

1 I. Yin RK. Estudo de caso: planejamento e métodos. $2^{\mathrm{a}}$ ed. Porto Alegre: Bookman; 2001.

12. Ministério da Saúde (BR). Conselho Nacional de Saúde. Resolução 196, de 10 de outubro de 1996: diretrizes e normas regulamentadoras de peseuisa envolvendo seres humanos. Bioética 1996; 4(2 supl): 15-25.

13. Xavier SA. Importância da comunicação na fidelização de doadores de sangue perspectiva de enfermagem. ABO: Rev Medd Transfus 2002; 12(1): 1 1-4.

14. Carazzato JG. Lesões musculotendíneas e seu tratamento. Rev Bras Ortop Traumatol 1994.

15. Cremers MI. latrogenia em endoscopia: parte II. I Port Gastrenterol 2006; 13(1): 26-39.

16. Bordin JO, Langhi Junior DM, Covas DT. Hemoterapia: fundamentos e prática. São Paulo: Atheneu; 2007.

17. Witt RR, Almeida MCP. Competências dos profissionais de saúde no referencial das funções essenciais de saúde pública: contribuição para a construção de projetos pedagógicos na enfermagem. Rev Bras Enferm 2003; 56(4): 329-32. 